\title{
Optimizing tissue sampling for the diagnosis, subtyping, and molecular analysis of lung cancer
}

\section{Linda Marie Ofiara $^{1}{ }^{*}$, Asma Navasakulpong $^{1,2}$, Stephane Beaudoin ${ }^{1}$ and Anne Valerie Gonzalez ${ }^{1}$}

${ }^{1}$ Respiratory Medicine Division, Department of Medicine, McGill University Health Centre, Montreal Chest Institute, Montreal, OC, Canada

2 Pulmonary and Respiratory Critical Care Division, Faculty of Medicine, Prince of Songkla University, Hatyai, Thailand

\section{Edited by:}

Barbara Melosky, British Columbia

Cancer Agency, Canada

Reviewed by:

Rabab Mohamed Gaafar, Cairo

University, Egypt

Jacobus A. Burgers, Antoni van

Leeuwenhoek Hospital, Netherlands

*Correspondence:

Linda Marie Ofiara, Montreal General Hospital, Room D7.201, 1650 Cedar

Avenue, Montreal, OC H3G 1A4,

Canada

e-mail: linda.ofiara@mcgill.ca
Lung cancer has entered the era of personalized therapy with histologic subclassification and the presence of molecular biomarkers becoming increasingly important in therapeutic algorithms. At the same time, biopsy specimens are becoming increasingly smaller as diagnostic algorithms seek to establish diagnosis and stage with the least invasive techniques. Here, we review techniques used in the diagnosis of lung cancer including bronchoscopy, ultrasound-guided bronchoscopy, transthoracic needle biopsy, and thoracoscopy. In addition to discussing indications and complications, we focus our discussion on diagnostic yields and the feasibility of testing for molecular biomarkers such as epidermal growth factor receptor and anaplastic lymphoma kinase, emphasizing the importance of a sufficient tumor biopsy.

Keywords: lung cancer, diagnosis, ultrasound bronchoscopy, diagnostic yield, transthoracic needle aspiration, molecular biomarkers, EGFR

\section{INTRODUCTION}

Lung cancer remains the leading cause of cancer death in North America. In Canada, an estimated 25,500 Canadians will be diagnosed with lung cancer in 2014 (1). The majority of these will be non-small cell lung cancer (NSCLC) and unresectable.

At diagnosis, $75 \%$ of lung cancer patients will have either locally advanced or metastatic disease (2). The goal in this group of patients is to establish the diagnosis and, ideally, confirm staging with the least invasive technique possible. As a result of this approach, biopsy specimens are becoming increasingly smaller. Up to $80 \%$ of patients receiving chemotherapy for advanced disease will have only a small biopsy and/or cytology samples available for diagnosis (3).

The adequacy of these samples has important ramifications. Lung cancer has entered an era of personalized therapy with treatment based on histologic subtypes (adenocarcinoma versus squamous) and the presence of molecular markers [epidermal growth factor receptor (EGFR) and anaplastic lymphoma kinase (ALK)]. For instance, several trials have demonstrated that response rate and overall survival is significantly better with pemetrexed in patients with non-squamous histology compared with patients with squamous histology (4). Trials using tyrosine kinase inhibitors (TKIs) have observed that patients with NSCLC tumors harboring EGFR mutations derive a greater benefit from treatment with TKIs than wild-type tumors (5). In fact, a number of trials have consistently shown a statistically significant and clinically meaningful benefit of TKIs over standard chemotherapy in mutation positive patients (5-7). The ALK inhibitor, crizotinib, is effective in patients with NSCLC harboring the ALK rearrangement (8).

Procurement of adequate tissue samples that allow for accurate characterization of histology and molecular testing is essential. A multidisciplinary approach is recommended. Physicians who obtain tissue samples (respirologists, interventional radiologists, and thoracic surgeons) need to be aware of the tissue yields of their procedures. Likewise, pathologists need to communicate the tissue yields and to be judicious in tissue use especially when managing small biopsy and cytology specimens. Finally, medical oncologists should be aware of when to ask for more tissue in patients in whom the treatment plan will be significantly impacted by further characterization. Medical oncologist may recommend that a patient with a known lung cancer be rebiopsied or that a metastatic site be biopsied in addition to the primary site in order to clarify the molecular status of the tumor. This can provide important information with regard to treatment options or as to why therapies fail.

In this article, techniques used in the diagnosis of lung cancer will be discussed including the expected tissue yields and the feasibility of histologic characterization and molecular testing.

\section{DIAGNOSIS OF LUNG CANCER}

\section{RAPID ASSESSMENT CLINICS}

Lung cancer guidelines recommend prompt investigation and referral for treatment (9).

Recently, rapid access clinics have been developed to reduce wait times and initiate investigations based on established algorithms to provide the most information about diagnosis and staging with the least risk to the patient. Bronchoscopy with or without lymph node sampling is frequently recommended as the initial diagnostic procedure.

\section{FIBEROPTIC BRONCHOSCOPY}

The bronchoscope is one of the primary diagnostic tools in lung cancer. Flexible bronchoscopy, usually performed under local anesthesia and with minimal sedation, provides a thorough examination of all segmental bronchi within minutes. Complications for this procedure are rare, with major complication rates 
between 0.08 and 5\% (10). Complications include pneumothorax, hypoxemia, and hemorrhage (11).

Endobronchial tumor may be visible as an exophytic mass or submucosal infiltration (Figure 1A). The diagnostic yield for endobronchial biopsy when a lesion is visible is $70-90 \%$ (12). Five biopsy specimens have been shown to be optimal for achieving a diagnostic yield in central lesions (13). Combining the results of bronchial biopsy, bronchial brushing, and bronchial washing increases tissue yields (14), and it is better to do brushing after biopsy (15).

Biopsy specimens are, in general, small averaging about 300 cells in aggregate. Bronchial lavage yields the least number of malignant cells. In biopsy specimens, the percentage (\%) of tumor cells can be relatively low. Coghlin et al. found the mean $\%$ of area of tumor in an endobronchial sample to be 33\%. In fewer than half of their cases (48\%), tumor was found in all biopsy specimens (16). Although five specimens may be enough to establish the diagnosis of lung cancer, the number of specimens required to provide detailed sub classification and molecular analysis has not be established. In one series, EGFR testing could be performed in 100\% of endobronchial biopsy specimens that established a diagnosis of lung cancer (17).

Endobronchial cryobiopsies could be one evidence-based way of achieving a higher diagnostic yield and a higher molecular analysis potential. Compared with conventional bronchoscopic biopsies, cryobiopsies result in an increase in biopsy sample size and yield $(18,19)$.

In the case of more peripheral lesions, when the endobronchial exam is normal, the diagnostic yield falls to $40 \%(20,21)$. The diagnostic yield can be increased when computed tomography (CT)

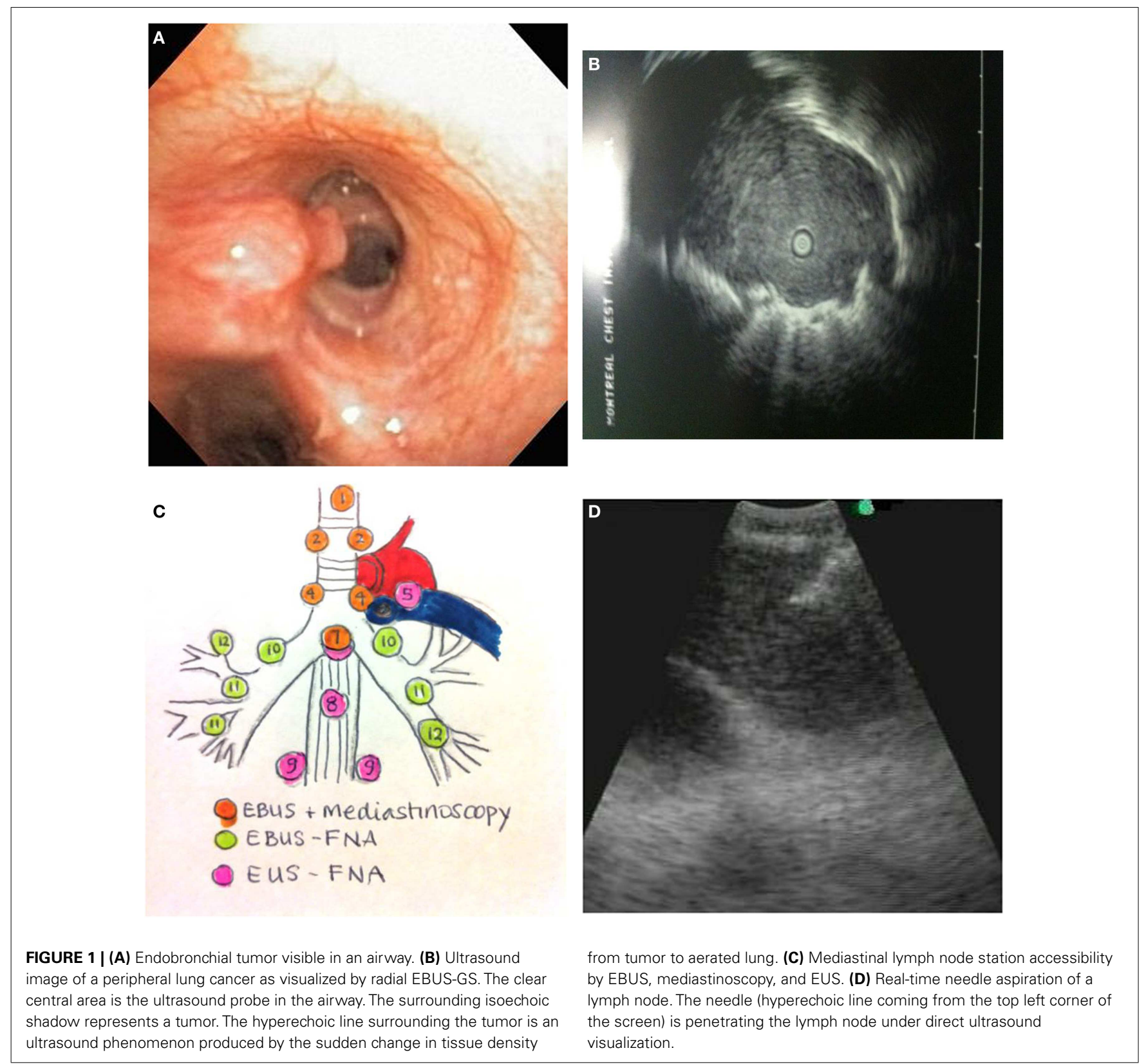


images are available for review prior to bronchoscopy (22). This allows the bronchoscopist to better localize the bronchial segment containing tumor. When positive, the diagnoses in these cases are usually made on the basis of cytology: bronchial brushings or washings. Molecular markers can be performed on these cytological specimens with varying degrees of success. One series, however, found that in the case of bronchial lavage, more than half of the cytological specimens that confirmed the diagnosis of lung cancer could not be used for molecular testing (23).

Ultrasonography using a guide sheath (radial EBUS-GS) and electromagnetic navigation (ENB) can provide transbronchial biopsy specimens, improving the possibility of having adequate tissue for molecular analysis. In the case of a peripheral lesion where the endobronchial exam is negative and radial EBUS-GS or ENB are not available, consideration should be given to other diagnostic procedures such as transthoracic needle aspirate.

\section{RADIAL EBUS}

Endobronchial ultrasonography using a sheath guide (EBUS-GS) can increase the diagnostic yield of peripheral lung lesions. For lesions less than $2 \mathrm{~cm}$, the diagnostic yield can increase from 36\% using conventional bronchoscopy to between 58 and 70\% (24). This technique allows for visualization of the lesion (Figure 1B) and repeated access to the lesion by brush, forceps biopsy, and bronchial wash. The resulting specimens are cytological and small biopsies.

Recently, ENB and virtual bronchoscopic navigation system (VBNS) have been developed to assist the diagnosis of peripheral lung lesions in conjunction with EBUS-GS. Using ENB, yields in peripheral lesions can be further improved upon. Combining radial EBUS and ENB resulted, in one series, in a diagnostic yield approaching $90 \%$ compared with $69 \%$ for radial EBUS alone (25). No EMN complications have been reported. VBNS has also been used with EBUS-GS with an overall diagnostic yield ranging from 63.3 to $84.4 \%$, and in lesions less than $2 \mathrm{~cm}$ in diameter, ranging from 44 to $75.9 \%$ (26). VBNS increases diagnostic yield and decreases procedure time (27). Presently, there is little data on the yield of molecular testing on specimens obtained by EBUS-GS or ENB/VBNS. Tsai et al. performed EBUS-guided brushings in 122 patients with peripheral lung cancer receiving flexible bronchoscopy. The yield for tumor cells was $68.9 \%$. Genotyping of EGFR and KRAS was successfully implemented in $80(95.2 \%)$ of the 84 cytology-proven brushing samples (28). It is probable that the yields are similar to conventional bronchoscopy as the specimens obtained are small biopsies and bronchial brushing/lavage cytology.

\section{EBUS TRANSBRONCHIAL NEEDLE ASPIRATION}

Endobronchial ultrasound-guided transbronchial needle aspiration (EBUS-TBNA) is a minimally invasive technique with a high diagnostic yield for mediastinal lymph node staging of lung cancer patients. Accurate staging is an essential step in the investigation of lung cancer patients. EBUS-TBNA is particularly useful as diagnosis and staging can be achieved with a single procedure.

The technique is performed using a dedicated flexible bronchoscope with an integrated ultrasound transducer. It allows for sampling of mediastinal and hilar lymph nodes under direct vision using local anesthesia and moderate sedation. The upper and lower paratracheal, prevascular, subcarinal, and hilar lymph node stations can all be sampled using this technique (Figure 1C).

A similar technique using a gastroscope with an integrated ultrasound probe (EUS) can also sample mediastinal lymph nodes. Nodal stations that can be accessed with EUS include aortopulmonary window, subcarinal, para-esophageal, and pulmonary ligament.

Herth et al. assessed EBUS yields in 502 patients with suspected lung cancer, comparing EBUS-TBNA results with operative findings (29). The reported sensitivity was $94 \%$ and specificity was $100 \%$. Several studies have compared EBUS-TBNA to mediastinoscopy and found both techniques to have comparable results for mediastinal staging $(30,31)$. EBUS-TBNA has some advantages over mediastinoscopy, in that EBUS-TBNA can be used to restage a patient post surgery or radiation therapy, where a repeat mediastinoscopy would prove difficult because of fibrotic changes (32). Additionally, it can be performed in high-risk patients with several comorbidities such as COPD (33).

Tissue samples by EBUS-TBNA are typically small cytology samples obtained using a dedicated 22 gage needle (Figure 1D). Some institutions use rapid on-site evaluation (ROSE) of aspirated samples by a cytopathologist. One of the main advantages of ROSE is reduction of the number of passes and stations sampled, and avoidance of other biopsy techniques like transbronchial biopsy. Lee and colleagues have demonstrated that maximum diagnostic values for achieving a diagnosis of lung cancer are achieved with three aspirations per node when ROSE is not available (34). Molecular testing for EGFR and ALK mutations can be successfully performed on EBUS-TBNA specimens. In several series, using ROSE, molecular testing can be performed in between 70 and $90 \%$ of EBUS-TBNA samples (35-37). Yarmus et al. found that a median of four passes in the presence of ROSE provided an adequate amount of tissue for molecular analysis in 95\% of patients studied (38). In the absence of ROSE, Navasakulpong and colleagues found that $93 \%$ of EBUS-TBNA specimens from a single lymph node station were adequate for EGFR testing with an average of 3.5 passes per lymph node. The minimum tumor cell count that allowed for successful EGFR testing in this series was 100 cells (39). Schmid-Bindert et al. found that EBUS-TBNA provided the highest yield for biomarker testing when compared to bronchoscopic forceps biopsy and CT-guided core biopsy (17).

Questions that remain to be answered are whether a larger needle (21 gage) results in better yields, whether mixing tissue from more than one lymph node station, once staging is established, can improve the yield of molecular testing, and finally, whether combining EBUS and EUS increases tissue yields for molecular analysis.

\section{MEDIASTINOSCOPY}

Cervical mediastinoscopy is used predominantly in the staging of lung cancer. It is performed by a thoracic surgeon under general anesthesia in an operating room. A small incision is made at the base of the neck and a mediastinoscope is introduced. The sensitivity of mediastinoscopy for detecting cancer in mediastinal lymph nodes is between 80 and 95\% $(32,40)$. False negative rates vary between 5 and $9 \%$ and are attributed to the 
inability to access para-esophageal, inferior pulmonary ligament, and aortopulmonary nodes.

Tissue samples vary from millimeters to centimeters depending on the size of the nodes biopsied. Tissue samples are sufficient for molecular testing. The complication rate is between 2 and $5 \%$ and includes hoarseness, infection, and bleeding (41).

Several series have compared EBUS to mediastinoscopy (42). Both modalities have comparable sensitivities in staging the mediastinum. Mediastinoscopy has the advantage of larger tissue samples, compared with EBUS. It is unclear if this translates into better molecular subtyping as little comparative data exist. The disadvantage of mediastinoscopy is the need for general anesthesia and OR time.

\section{TRANSTHORACIC NEEDLE ASPIRATE}

A total of 10-20\% of cases of NSCLC will present as a solitary pulmonary nodule. In patients who are not candidates for surgery or in patients who have advanced disease in whom the most accessible site for biopsy is a peripheral lung nodule, transthoracic needle aspiration (TTNA) and biopsy (TTNB) are useful diagnostic procedures.

Transthoracic needle aspiration can be performed under CT or fluoroscopic guidance. CT-guided aspiration and biopsies result in a higher diagnostic yield compared to fluoroscopy (43).The most commonly used technique is a coaxial system, in which a larger gage needle is inserted into the edge of the lesion and a smaller needle is passed through the larger one. This allows for a single pleural puncture and repeat needle passes by the smaller needle reducing the risk of complications. Major complications are bleeding and pneumothorax and occur in $10 \%$ and up to $20 \%$ of cases, respectively (44). Contraindications to TTNA are previous pneumonectomy, severe chronic obstructive lung disease, especially with bullous formation, mechanical ventilation, lesions too close to vascular structures, and high risk for bleeding (45).

Transthoracic needle aspiration has a diagnostic accuracy of between 80 and 95\% for lung cancer $(46,47)$. Specimens obtained by TTNA are cutting-needle core biopsies and needle aspirate cytology. Core-needle biopsy specimens usually contain enough cellular material for pathologic subtyping and molecular analysis. The average number of cells obtained by CT-guided needle biopsy is 500 cells per biopsy (48). Zhuang et al. showed that CT-guided TTNA/TTNB performed using an 18 or 20 gage could obtain tumor samples ranging from 0.5 to $1.5 \mathrm{~cm}$ in length and that these samples were 100\% adequate for histological and EGFR mutation analysis (49). In addition, Fassina et al. showed that TTNA samples can be used for EGFR and KRAS mutation analysis (50). da Cunha Santos et al. found that in a review of 602 fine needle aspirates, histological subtyping agreement with resected specimens was achieved in $93 \%$ of cases (51).

\section{PLEURAL FLUID ANALYSIS AND MEDICAL THORACOSCOPY}

In rapid diagnostic clinics for the evaluation of suspected lung cancer, diagnostic procedures that allow for simultaneous staging and diagnosis are preferred. In patients with suspected lung cancer presenting with an accessible pleural effusion, thoracentesis is recommended to distinguish between a malignant versus parapneumonic effusion (21). The yield of pleural fluid cytology is
$60-80 \%$ with repeat sampling $(52,53)$. Use of cell block methods improves the diagnostic utility of pleural cytology compared with conventional smear cytology by providing higher cellularity and better morphological features to allow for pathologic subtyping. Using cell blocks of pleural fluid, molecular testing for EGFR and KRAS has been performed with an insufficiency rate of 3.7\% (1 in 27 specimens) (54).

Medical thoracoscopy is recommended when cytology specimens are non-diagnostic or insufficient for histologic classification. It offers higher yield compared with Abrams needle and CT-guided pleural biopsy in malignant pleural disease (55). In addition to being able to directly visualize and biopsy nodules on the parietal pleural surface, thoracoscopy allows for drainage of pleural fluid and talc pleurodesis in the case of malignant effusions.

Medical thoracoscopy can be performed in a dedicated sterile endoscopy suite under local anesthesia and conscious sedation. A pneumothorax is artificially induced, and a rigid thoracoscope is introduced into the pleural cavity. Under direct vision, parietal pleural nodules can be biopsied. The diagnostic yield of medical thoracoscopy for malignancy is $93-97 \%$ (56). Biopsy specimens are typically about $5 \mathrm{~mm}$ and multiple specimens can be obtained during the procedure. The size of these specimens is adequate for pathological subtyping, and molecular analysis was possible in $100 \%$ of specimens tested in one series (57).

Medical thoracoscopy is a relatively safe procedure with a complication rate of $1.9 \%$ (58). Persistent air leak, subcutaneous emphysema, and fever are the most common complications. Mortality is rare with 1 death reported in more than 8000 cases (53).

\section{TISSUE STRATEGIES FOR PATHOLOGICAL SUBTYPING AND MOLECULAR ANALYSIS}

Strategies have been proposed to allow for subtyping of NSCLC and testing of molecular markers in small biopsy and cytology specimens (59). With any specimen, the first approach is to establish squamous or adenocarcinoma differentiation based on morphology under light microscopy. The typical features of adenocarcinoma include glandular differentiation of cell clusters and in individual cells, the presence of basophilic cytoplasm, eccentric nuclei, and a single macronucleolus. Squamous differentiation is characterized by keratinization, intercellular bridges, and keratin pearls in small biopsies. Individual cells may have long cytoplasmic tails, central nuclei, dense chromatin, and poorly developed nucleoli.

In cases of NSCLC that cannot be subtyped based on morphology, immunohistochemistry (IHC) is used. Because of the small amounts of tissue, IHC should be used judiciously. It is recommended to use one adenocarcinoma marker (TTF1) and one squamous marker (p63 or CK 5/7) to attempt to further subtype NSCLC (60).

In the case of adenocarcinoma, molecular markers can then be performed. Currently, EGFR and ALK are performed, but other markers such as ROS1 and KRAS may also be considered. In tumors that cannot be subtyped based on morphology and IHC, a designation of NSCLC not otherwise specified (NOS) is made. Decisions can be made whether additional tissue is warranted; however, recommendations for EGFR testing include specimens designated as NSCLC-NOS (61). 
Table 1 |Yields of various procedures used to diagnose lung cancer.

\begin{tabular}{|c|c|c|c|}
\hline Diagnostic modality & Specimen types & Diagnostic yield & Adequacy for biomarker testing \\
\hline \multirow[t]{3}{*}{ Bronchoscopy } & Endobronchial biopsy & 70-90\% (if lesion visible) & Up to $100 \%$ in one series for endobronchial biopsy. \\
\hline & Brushing cytology & Yields improve when biopsy, & Less than $50 \%$ in washings \\
\hline & Washing cytology & brushing, and washing combined & \\
\hline Radial EBUS-GS & Transbronchial biopsy & 58-70\% when biopsy, brushing, & $71 \%$ in one series examining bronchial brushing \\
\hline For peripheral lesions & Brushing cytology & and washings combined & \\
\hline $2 \mathrm{~cm}$ or less & Washing cytology & & \\
\hline EBUS-TBNA & Needle aspirate cytology & Up to $94 \%$ & $70-95 \%$ \\
\hline Mediastinoscopy & Biopsy & $80-95 \%$ & Not well established, but likely adequate based on size \\
\hline \multirow[t]{2}{*}{ CT-guided TTNA } & Core-needle biopsy & $80-95 \%$ & $100 \%$ in one series \\
\hline & Needle aspirate & & \\
\hline Thoracentesis & Fluid cytology & $60-80 \%$ & Insufficiency rate of $3.7 \%$ in one series \\
\hline Medical thoracoscopy & Biopsy & $93-97 \%$ & $100 \%$ in one series \\
\hline
\end{tabular}

The minimum number of malignant tumor cells required for molecular marker testing has not been well established. In general, larger samples with at least 200-400 malignant cells are preferred (62).

Communication among the multiple physicians involved in the care of patients with lung cancer must take into consideration issues of tissue procurement strategies in order to optimize diagnostic yield and molecular characterization of tumors. Only a multidisciplinary approach can ensure that the needs of the medical oncologist for treatment planning are reflected into judicious tissue procurement, clinical staging, and thoughtful tissue analysis. Moreover, local institutional strategies must be implemented to take into consideration the local availability of different diagnostic modalities and molecular analyses. Solutions regarding issues of cost-effectiveness and quality control must be individualized for each center, and ongoing monitoring is important to ensure that safe and efficient diagnostic services are delivered. This is especially important given that many of the above-mentioned technologies have mostly been studied only in highly specialized centers.

\section{SUMMARY AND RECOMMENDATIONS}

A sufficient tumor biopsy is essential in the diagnosis of lung cancer in order to subtype NSCLC and to establish the presence molecular markers. Important therapeutic decisions are made on the basis of these specimens. In this article, we have summarized the various techniques used in the diagnosis of lung cancer and their respective yields in terms of tissue, pathological subtype, and molecular testing. Table 1 summarizes the diagnostic yields of specimens obtained.

A multidisciplinary approach in establishing a diagnosis of lung cancer is strongly recommended to optimize tissue yields and ultimately patient outcomes. In general, the least invasive procedure should be favored and biopsy specimens favored over cytology specimens. There is, however, increasing evidence to suggest that, when handled judiciously, cytology specimens can prove to be sufficient for diagnosis and molecular analysis. Understanding the yields of diagnostic procedures is essential in diagnosing and treating lung cancer in an era of personalized therapy.

\section{REFERENCES}

1. Advisory Committee on Cancer Statistics. Canadian Cancer Statistics. Toronto, ON: Canadian Cancer Society (2013).

2. Pfister DG, Johnson DH, Azzoli CG, Sause W, Smith TJ, Baker S Jr, et al. American Society of Clinical Oncology. Treatment of unresectable non-small cell lung cancer guideline: update 2003. J Clin Oncol (2004) 22:330-53. doi:10.1200/JCO.2004.09.053

3. Kerr KM. Personalized medicine for lung cancer: new challenges for pathology. Histopathology (2012) 60:531-46. doi:10.1111/j.1365-2559.2011.03854.x

4. Scagliotti G, Hanna N, Fossella F, Sugarman K, Blatter J, Peterson P, et al. The differential efficacy of pemetrexed according to NSCLC histology: a review of two phase III studies. Oncologist (2009) 14:253-63. doi:10.1634/theoncologist. 2008-0232

5. Rosell R, Carcereny E, Gervais R, Vergnenegre A, Massuti B, Felip E, et al. Erlotinib versus standard chemotherapy as first-line treatment for European patients with advanced EGFR mutation positive non-small cell lung cancer (EURTAC) a multicentre, open-label randomized phase 3 trial. Lancet Oncol (2012) 13:239-46. doi:10.1016/S1470-2045(11)70393-X

6. Zhou C, Wu YL, Chen G, Feng J, Liu XQ, Wang C, et al. Erlotinib versus chemotherapy as first line treatment for patients with advanced EGFR mutation positive non-small cell lung cancer (OPTIMAL, CTONG-0802): a multicentre, open label, randomized phase 3 trial. Lancet Oncol (2011) 12:435-42. doi:10.1016/S1470-2045(11)70184-X

7. Wu YL, Zhou C, Hu C-P, Feng JF, Lu S, Huang Y, et al. LUX-Lung 6: a randomized, open label phase 3 study of Afatanib versus gemcitabine-cisplatin as first line treatment for Asian patients with EGFR mutation positive advanced adenocarcinoma. J Clin Oncol (2013) 31(Suppl):490s, abstr8016.

8. Kwak EL, Bang YJ, Camidge DR, Shaw AT, Solomon B, Maki RG, et al. Anaplastic lymphoma kinase inhibition in non-small cell lung cancer. N Engl J Med (2010) 363:1693-703. doi:10.1056/NEJMoa1006448

9. Baldwin DR, White B, Schmidt-Hansen M, Champion AR, Melder AM, Guideline Development Group. Diagnosis and treatment of lung cancer: summary of updated NICE guidance. BMJ (2011) 342:d2110. doi:10.1136/bmj.d2110

10. Simpson FG, Arnold AG, Purvis A, Belfield PW, Muers MF, Cooke NJ. Postal survey of bronchoscopic practice by physicians in the United Kingdom. Thorax (1986) 41:311-7. doi:10.1136/thx.41.4.311

11. British Thoracic Society Bronchoscopy Guidelines Committee, a subcommittee of the Standards of Care Committee of the British Thoracic Society. British Thoracic Society guidelines on diagnostic flexible bronchoscopy. Thorax (2001) 56(Suppl 1):i1-21. doi:10.1136/thx.56.suppl_1.i1 
12. Mazzone P, Jain P, Arroliga AC, Matthay RA. Bronchoscopy and needle biopsy techniques for diagnosis and staging of lung cancer. Clin Chest Med (2002) 23:137-58. doi:10.1016/S0272-5231(03)00065-0

13. Gellert AR, Rudd RM, Sinha G, Geddes DM. Fiberoptic bronchoscopy: effect of multiple biopsies on diagnostic yield in bronchial carcinoma. Thorax (1982) 37:684-7. doi:10.1136/thx.37.9.684

14. Bodh A, Kaushal V, Kashap S, Gutali A. A cytohistological correlation in diagnosis of lung tumours by using fiberoptic bronchoscopy: study of 200 cases. Indian J Pathol Microbiol (2013) 56:84-8. doi:10.4103/0377-4929.118661

15. Chen WT, Chao TY, Wu CP, Perng WC, Shen CY, Chiang CH. Comparison of the diagnostic yield of bronchial brushing cytology before and after endobronchial biopsy of flexible fiberoptic bronchoscopy - a prospective study. J Med Sci (1997) 18:165-70.

16. Coghlin CL, Smith LJ, Bakar S, Stewart KN, Devereux GS, Nicolson MC, et al. Quantitative analysis of tumor in bronchial biopsy specimens. J Thorac Oncol (2010) 5:448-52. doi:10.1097/JTO.0b013e3181ca12c4

17. Schmid-Bindert G, Wang Y, Jiang H, Sun H, Henzler T, Wang H, et al. EBUSTBNA provides highest RNA yield for multiple biomarker testing from routinely obtained small biopsies in non-small cell lung cancer patients - a comparative study of three different minimal invasive sampling methods. PLoS One (2013) 8(10):e77948. doi:10.1371/journal.pone.0077948

18. Hetzel J, Eberhardt R, Herth FJ, Petermann C, Reichle G, Freitag L, et al. Cryobiopsy increases the diagnostic yield of endobronchial biopsy: a multicentre trial. Eur Respir J (2012) 39:685-90. doi:10.1183/09031936.00033011

19. Schumann C, Hetzel J, Babiak AJ, Merk T, Wibmer T, Möller P, et al. Cryoprobe biopsy increases the diagnostic yield in endobronchial tumor lesions. J Thorac Cardiovasc Surg (2010) 140:417-21. doi:10.1016/j.jtcvs.2009.12.028

20. Baaklini WA, Reinoso MA, Gorin AB, Sharafkaneh A, Manian P. Diagnostic yield of fiberoptic bronchoscopy in evaluating solitary pulmonary nodules. Chest (2000) 117:1049-54. doi:10.1378/chest.117.4.1049

21. Rivera MP, Mehta AC, American College of Chest Physicians. Initial diagnosis of lung cancer. ACCP evidence based clinical practice guidelines. Chest (2007) 132(Suppl 3):131S-48S. doi:10.1378/chest.07-1357

22. Laroche C, Fairbairn I, Moss H, Pepke-Zaba J, Sharples L, Flower C, et al. Role of computed tomographic scanning of the thorax prior to bronchoscopy in the investigation of suspected lung cancer. Thorax (2000) 55:359-63. doi:10.1136/thorax.55.5.359

23. Allegrini S, Antona J, Mezzapelle R, Miglio U, Paganotti A, Veggiani C, et al. Epidermal growth factor receptor gene analysis with a highly sensitive molecular assay in routine cytologic specimens of lung adenocarcinoma. Am J Clin Pathol (2012) 138:377-81. doi:10.1309/AJCPVAGIUC1AHC3Y

24. Kurimoto N, Nakamura H, Miyazawa T. Overview of endobronchial ultrasonography in chest medicine. J Med Ultrasound (2009) 17:31-43. doi:10.1016/S09296441(09)60013-8

25. Eberhardt R, Anantham D, Ernst A, Feller-Kopman D, Herth F. Multimodality bronchoscopic diagnosis of peripheral lung lesions. A randomized controlled trial. Am J Respir Crit Care Med (2007) 176:37-41. doi:10.1164/rccm.2006121866OC

26. Asahina H, Yamazaki K, Onodera Y, Kikuchi E, Shinagawa N, Asano F, et al. Transbronchial biopsy using endobronchial ultrasonography with a guide sheath and virtual bronchoscopic navigation. Chest (2005) 128:1761-5. doi:10.1378/ chest.128.3.1761

27. Asano F, Matsuno Y, Tsuzuku A, Anzai M, Shinagawa N, Yamazaki K, et al. Diagnosis of peripheral pulmonary lesions using a bronchoscope insertion guidance system combined with endobronchial ultrasonography with a guide sheath. Lung Cancer (2008) 60:366-73. doi:10.1016/j.lungcan.2007.10.022

28. Tsai TH, Yang CY, Ho CC, Liao WY, Jan IS, Chen KY, et al. Multi-gene analyses from waste brushing specimens for patients with peripheral lung cancer receiving EBUS-assisted bronchoscopy. Lung Cancer (2013) 82(3):420-5. doi:10.1016/j.lungcan.2013.10.005

29. Herth FJ, Eberhardt R, Vilmann P, Krasnik M, Ernst A. Real-time endobronchial ultrasound guided transbronchial needle aspiration for sampling mediastinal lymph nodes. Thorax (2006) 61:795-8. doi:10.1136/thx.2005.047829

30. Annema JT, van Meerbeeck JP, Rintoul RC, Dooms C, Deschepper E, Dekkers OM, et al. Mediastinoscopy vs endosonography for mediastinal nodal staging of lung cancer: a randomized trial. JAMA (2010) 304:2245-52. doi:10.1001/jama. 2010.1705
31. Almeida FA, Uzbeck M, Jimenez C, Morice R, Rice D, Ost D, et al. Flexible bronchoscopy and endobronchial ultrasound needle aspiration (EBUS-TBNA) vs other invasive modalities in the initial diagnosis and staging of suspected or confirmed lung cancer. Chest (2010) 138:423A.Abstract. doi:10.1378/chest.10655

32. Herth FJ. Nonsurgical staging of the mediastinum: EBUS and EUS. Semin Respir Crit Care Med (2011) 32:62-8. doi:10.1055/s-0031-1272870

33. Nakajima T, Yasufuku K, Nakajima M, Baba M, Yoshikawa K, Kamada T, et al. Endobronchial ultrasound-guided transbronchial needle aspiration for lymph node staging in patients with non-small cell lung cancer in non- operable patients pursuing radiotherapy as a primary treatment. J Thorac Oncol (2010) 5:606-11. doi:10.1097/JTO.0b013e3181d35627

34. Lee HS, Lee GK, Lee HS, Kim MS, Lee JM, Kim HY, et al. Real-time endobronchial ultrasound-guided transbronchial needle aspiration in mediastinal staging of non-small cell lung cancer: how many aspirations per target lymph node station? Chest (2008) 134:368-74. doi:10.1378/chest.07-2105

35. Nakajima T, Yasufuku K, Suzuki M, Hiroshima K, Kubo R, Mohammed S, et al. Assessment of epidermal growth factor receptor mutation by endobronchial ultrasound-guided transbronchial needle aspiration. Chest (2007) 132(2):597-602. doi:10.1378/chest.07-0095

36. Schuurbiers OC, Looijen-Salamon MG, Ligtenberg MJ, van derHeijden HF. A brief retrospective report on the feasibility of epidermal growth factor receptor and KRAS mutation analysis in transesophageal and endobronchial ultrasoundguided fine needle cytological aspirates. J Thorac Oncol (2010) 5(10):1664-7. doi:10.1097/JTO.0b013e3181f0bd93

37. Garcia-Olive I, Monso E, Andreo F, Sanz-Santos J, Taron M, Molina-Vila MA, et al. Endobronchial ultrasound-guided transbronchial needle aspiration for identifying EGFR mutations. Eur Respir J (2010) 35(2):391-5. doi:10.1183/ 09031936.00028109

38. Yarmus L, Akulian J, Gilbert C, Feller-Kopman D, Lee HJ, Zarogoulidis P, et al. Optimizing endobronchial ultrasound for molecular analysis. How many passes are needed? Ann Am Thorac Soc (2013) 10(6):636-43. doi:10.1513/AnnalsATS. 201305-130OC

39. Navasakulpong A, Jung S, Gonzalez AV. Implementation and feasibility of EGFR testing using endobronchial ultrasound guided needle aspirates (EBUS-TBNA) in patients with non-small cell lung cancer. Abstract accepted ATS May 2014 presentation.

40. Toloza EM, Harpole L, Detterbeck F, McCrory DC. Invasive staging of non-small cell lung cancer: a review of the current evidence. Chest (2003) 123:157S-66S. doi:10.1378/chest.123.1_suppl.157S

41. Lemaire A, Nikolic I, Petersen T, Haney JC, Toloza EM, Harpole DH Jr, et al. Nine-year single center experience with cervical mediastinoscopy: complications and false negative rate. Ann Thor Surg (2006) 82(4):1185-9. doi:10.1016/ j.athoracsur.2006.05.023

42. Yasufuku K, Pierre A, Darling G, de Perrot M, Waddell T, Johnston M, et al. A prospective controlled trial of endobronchial ultrasound-guided transbronchial needle aspiration compared with mediastinoscopy for mediastinal lymph node staging of lung cancer. J Thorac Cardiovasc Surg (2011) 142(13931400):e1391. doi:10.1016/j.jtcvs.2011.08.037

43. Schreiber G, McCrory DC. Performance characteristics of different modalities for diagnosis of suspected lung cancer: summary of published evidence. Chest (2003) 123:115S-28S. doi:10.1378/chest.123.1_suppl.115S

44. Klein JS, Salomon G, Stewart EA. Transthoracic needle biopsy with a coaxially placed 20-gauge automated cutting needle: results in 122 patients. Radiology (1996) 198:715-20. doi:10.1148/radiology.198.3.8628859

45. Bolliger CT, Mathur PN, Beamis JF, Becker HD, Cavaliere S, Colt H, et al. ERS/ATS statement on interventional pulmonology. European Respiratory Society/American Thoracic Society. Eur Respir J (2002) 19:365-73.

46. Laurent F, Latrabe V, Vergier B, Michel P. Percutaneous CT-guided biopsy of the lung: comparison between aspiration and automated cutting needles using a coaxial technique. Cardiovasc Interven Radiol (2000) 23:266-72. doi:10.1007/s002700010067

47. Levine MS, Weiss JM, Harrell JH, Cameron TJ, Moser KM. Transthoracic needle aspiration biopsy following negative fiberoptic bronchoscopy in solitary pulmonary nodules. Chest (1988) 93:1152-5. doi:10.1378/chest.93.6.1152

48. Pirker R, Herth FJ, Kerr KM, Filipits M, Taron M, Gandara D, et al. Consensus for EGFR testing in non-small cell lung cancer: results from a European workshop. J Thorac Oncol (2010) 5(10):1706-13. doi:10.1097/JTO.0b013e3181f1c8de 
49. Zhuang YP, Wang HY, Shi MQ, Zhang J, Feng Y. Use of CT-guided fine needle aspiration biopsy in epidermal growth factor receptor mutation analysis in patients with advanced lung cancer. Acta Radiol (2011) 52:1083-7. doi:10.1258/ar.2011.110150

50. Fassina A, Gazziero A, Zardo D, Corradin M, Aldighieri E, Rossi GP. Detection of EGFR and KRAS mutations on trans-thoracic needle aspiration of lung nodules by high resolution melting analysis. J Clin Pathol (2009) 62:1096-102. doi:10.1136/jcp.2009.067587

51. da Cunha Santos G, Lai SW, Saieg MA, Geddie WR, Pintilie M, Tsao MS, et al. Cyto-histologic agreement in pathologic subtyping of non-small cell lung carcinoma: review of 602 fine needle aspirates with follow-up surgical specimens over a nine year period and analysis of factors underlying failure to subtype. Lung Cancer (2012) 77(3):501-6. doi:10.1016/j.lungcan.2012.05.091

52. Sears D, Hajdu SI. The cytologic diagnosis of malignant neoplasms in pleural and peritoneal effusions. Acta Cytol (1987) 31:85-97.

53. Boutin C, Viallat JR, Cargnino P, Farisse P. Thoracoscopy in malignant pleural effusions. Am Rev Respir Dis (1981) 124:588-92.

54. Billah S, Stewart J, Staerkel G, Chen S, Gong Y, Guo M. EGFR and KRAS mutations in lung carcinoma: molecular testing by using cytology specimens. Cancer Cytopathol (2011) 119:111-7. doi:10.1002/cncy.20151

55. Rahman NM, Ali NJ, Brown G, Chapman SJ, Davies RJ, Downer NJ, et al. Local anaesthetic thoracoscopy: British Thoracic Society Pleural Disease Guideline 2010. Thorax (2010) 65(Suppl 2):ii54-60. doi:10.1136/thx.2010.137018

56. Roberts ME, Neville N, Berrisford RG, Antunes G, Ali NJ, et al. Management of a malignant pleural effusion. British thoracic society guidelines. Thorax (2010) 65(2):ii32-40. doi:10.1136/thx.2010.136994

57. Liu D, Lu Y, Hu Z, Wu N, Nie X, Xia Y, et al. Malignant pleural effusion supernatants are substitutes for metastatic pleural tumour tissues in EGFR mutation test in patients with advanced lung adenocarcinoma. PLoS One (2014) 9(2):e89946. doi:10.1371/journal.pone.0089946

58. Menzies R, Charbonneau M. Thoracoscopy for the diagnosis of pleural disease. Ann Intern Med (1991) 114:271-6. doi:10.7326/0003-4819-114-4-271

59. Travis WD, Brambilla E, Noguchi M, Nicholson AG, Geisinger K, Yatabe Y, et al. Diagnosis of lung cancer in small biopsies and cytology. Implications of the 2011 International Association for the Study of Lung Cancer/American Thoracic
Society/European Respiratory Society classification. Arch Pathol Lab Med (2013) 137:668-84. doi:10.5858/arpa.2012-0263-RA

60. Thunnissen E, Kerr KM, Herth FJ, Lantuejoul S, Papotti M, Rintoul RC, et al. The challenge of NSCLC diagnosis and predictive analysis on small samples. Practical approach of a working group. Lung Cancer (2012) 76:1-18. doi:10.1016/j.lungcan.2011.10.017

61. Lindeman NI, Cagle PT, Beasley MB, Chitale DA, Dacic S, Giaccone G, et al. Molecular testing guideline for selection of lung cancer patients for EGFR and ALK tyrosine kinase inhibitors: Guideline from the College of American Pathologists (CAP), International Association for the Study of Lung Cancer(IASLC), Association of Molecular Pathologists (AMP). Arch Pathol Lab Med (2013) 137(6):828-60. doi:10.5858/arpa.2012-0720-OA

62. Travis WD, Brambilla E, Noguchi M, Nicholson AG, Geisinger KR, Yatabe $\mathrm{Y}$, et al. International Association of the Study of Lung Cancer/American Thoracic Society/European Respiratory Society International Multidisciplinary Classification of Lung Adenocarcinoma. J Thorac Oncol (2011) 6(2):244-85. doi:10.1097/JTO.0b013e318206a221

Conflict of Interest Statement: The authors declare that the research was conducted in the absence of any commercial or financial relationships that could be construed as a potential conflict of interest.

Received: 01 May 2014; accepted: 03 September 2014; published online: 22 September 2014

Citation: Ofiara LM, Navasakulpong A, Beaudoin S and Gonzalez AV (2014) Optimizing tissue sampling for the diagnosis, subtyping, and molecular analysis of lung cancer. Front. Oncol. 4:253. doi: 10.3389/fonc.2014.00253

This article was submitted to Thoracic Oncology, a section of the journal Frontiers in Oncology.

Copyright (c) 2014 Ofiara, Navasakulpong, Beaudoin and Gonzalez. This is an openaccess article distributed under the terms of the Creative Commons Attribution License (CC BY). The use, distribution or reproduction in other forums is permitted, provided the original author(s) or licensor are credited and that the original publication in this journal is cited, in accordance with accepted academic practice. No use, distribution or reproduction is permitted which does not comply with these terms. 